Botero, A.; Marulanda, C.; Alvarez, M.; Muñoz, L. (2018). Proceso de implementación de las NIIF en Colombia: un acercamiento a las autoridades de vigilancia definidas en la Ley 1314 de 2009. Contaduría Universidad de Antioquia, 73, 131-162.

Doi: https://doi.org/10.17533/udea.rc.n73a06

\title{
Proceso de implementación de las NIIF en Colombia: un acercamiento a las autoridades de vigilancia definidas en la Ley 1314 de 2009
}

Ángela Susana Botero Bedoya susana.botero@udea.edu.co

Universidad de Antioquia

Camilo Marulanda Tejada camilo.marulandat@udea.edu.co Universidad de Antioquia

Lina María Muñoz Osorio lmaria.munoz@udea.edu.co

Universidad de Antioquia

Martha Cecilia Álvarez Osorio cecilia.alvarez@udea.edu.co

Universidad de Antioquia 
Proceso de implementación de las NIIF en Colombia: un acercamiento a las autoridades de vigilancia definidas en la ley 1314 de 2009

Resumen: Las Superintendencias y la Junta Central de Contadores, definidas en la Ley 1314 como autoridades de supervisión y autoridad disciplinaria, respectivamente, se convierten en un actor clave en el proceso de convergencia hacia Estándares Internacionales de Información Financiera, al ser las entidades responsables de vigilar el cumplimiento del mismo; sin embargo, es cuestionable el rol desempeñado por dichas autoridades y la ejecución a cabalidad de sus funciones. Para caracterizar el papel que han jugado se aplicaron entrevistas a personas vinculadas directamente con las autoridades en mención y encuestas a contadores con experticia en el tema, evidenciando que tales autoridades han presentado falencias que tienen un carácter histórico y que han dificultado la vigilancia del proceso de convergencia, puesto que la Junta Central de Contadores desde su creación ha funcionado reactivamente y la Superintendencia de Sociedades no logra dar cubrimiento a la multiplicidad de entidades.

Palabras clave: Normas Internacionales de Información Financiera, Autoridades de Vigilancia, Superintendencia de Sociedades, Junta Central de Contadores, Ley 1314 de 2009.

The process of IFRS implementation in Colombia: an approach to the surveillance authorities defined in Law 1314 of 2009

Abstract: The Superintendences and the Central Board of Accountants, defined in Law 1314 as surveillance authorities and disciplinary authority respectively, become key actors in the convergence process towards the International Financial Reporting Standards, for being the entities responsible of surveilling compliance with them. However, the role performed by said authorities and the fully execution of their functions are questioned. To characterize the role they have played, interviews were applied to people directly linked with the mentioned authorities, as well as surveys to accountants with expertise on the topic, evidencing that such authorities have observed a history of flaws that have made surveillance of the convergence process difficult, since from their creation, the Central Board of Accountants has worked reactively and the Superintendence of Companies has failed to attend to the multiplicity of entities.

Keywords: International Financial Reporting Standards, Surveillance Authorities, Superintendence of Companies, Central Board of Accountants, Law 1314 of 2009.

Processus d'implémentation des IFRS en Colombie : un rapprochement aux autorités de contrôle définis par la Loi 1314 de 2009

Résumé : la Loi 1314 définit las Superintendencias (surintendences) comme les autorités de contrôle et la Junta Central de Contadores (Conseil Central de Comptables) comme l'autorité disciplinaire. Ces organismes jouent un rôle essentiel au processus de convergence vers les International Financial Reporting Standards (IFRS) puisqu 'ils sont chargés de surveiller leur exécution. Toutefois, le rôle joué par ces organismes et la mise en ouvre de la totalité de leurs fonctions est bien questionnable. Afin de caractériser leur rôle, nous avons interviewé des personnes directement liées à ces organismes et nous avons menée un sondage avec des comptables experts dans la matière. Nous avons pu observer que ces organismes portent des failles à caractère historique qui font obstacle au contrôle du processus de convergence car, depuis sa création, la Junta Central de Contadores a agi réactivement. De sa part, la Superintendencia de Sociedades n'arrive pas à couvrir l'ensemble d'établissements.

Mots-clés : International Financial Reporting Standards, autorités de contôle, Superintendencia de sociedades, Junta Central de Contadores, Loi 1314 de 2009

Processo de implementação das normas NIIF na Colômbia: Uma aproximação às autoridades de vigilância definidas na lei 1314 de 2009

Resumo: As superintendências e a Junta Central de Contadores, definidas na lei 1314 como autoridades de supervisão e autoridade de disciplina, respectivamente, se tornam um ator chave no processo de convergência aos padrões internacionais de Informação Financeira, ao ser as entidades responsáveis de supervisar o cumprimento do mesmo. Porém, é questionável o papel desempenhado por tais autoridades e a execução adequada das suas funções. Para caracterizar o papel que jogam, fizeram-se entrevistas a pessoas vinculadas diretamente com as autoridades anteriormente mencionadas e enquetes a contadores com conhecimentos neste assunto, evidenciando que estas autoridades têm apresentado falhas de caráter histórico e que têm tornado dificil a supervisão do processo de convergência, já que a Junta Central de Contadores desde sua criação funciona reativamente e a Superintendência de Sociedades não consegue cobrir todas as entidades.

Palavras chave: Normas Internacionais da Informação Financeira, Autoridades de Supervisão, Superintendência de Sociedades, Junta Central de Contadores, Lei 1314 de 2009. 
Cont. udea (julio-diciembre), pp. 131-162. (C) Universidad de Antioquia-2018.

\title{
Proceso de implementación de las NIIF en Colombia: un acercamiento a las autoridades de vigilancia definidas en la Ley 1314 de 2009
}

\author{
Ángela Susana Botero Bedoya, Camilo Marulanda Tejada, \\ Lina María Muñoz Osorio, Martha Cecilia Álvarez Osorio \\ Doi: https://doi.org/10.17533/udea.rc.n73a06
}

Primera versión recibida en agosto de 2018 - Versión final aceptada en septiembre de 2018

\section{Introducción}

L

as Normas Internacionales de Información Financiera (NIIF), más que un conjunto de normas, son estándares que al ser acogidos por los países requieren que éstos desarrollen nuevas prácticas contables inducidas al logro de presentar información financiera con propósito general que sea de utilidad a los diferentes usuarios como inversores, prestamistas y otros acreedores existentes o potenciales. Países como Colombia han presentado dificultades a la hora de transitar hacia dicho proceso, debido a que por su idiosincrasia en el campo contable ha estado supeditado a las disposiciones legales expresas por el gobierno nacional, por lo cual a éste le correspondía evaluar los beneficios y perjuicios que supondría la presentación de información financiera bajo los parámetros de las NIIF.

En el año 2009 se da inicio al proceso de convergencia hacia estándares internacionales en Colombia y a partir de ello, se han venido desarrollando una serie de acciones para dar cumplimiento a lo establecido en la Ley 1314 del mismo año, tales como la definición de los tres grupos, siendo Grupo II y Grupo III los de mayor representatividad al estar compuesto por MIPYMES que representan el 99\% de las empresas colombianas (Departamento Nacional de Planeación [DNP], 2005) y para los cuales podría resultar más traumática la implementación debido, principalmente, a sus características propias y el alcance de las normas que para ellos se han definido.

Lo anterior, sumado al conocimiento derivado de otras investigaciones, denota que el proceso de implementación en dichas empresas no ha sido el más 
Botero, A.; Marulanda, C.; Alvarez, M.; Muñoz, L. Proceso de implementación de las NIIF...

propicio, lo cual responde a una serie de diversas causas, tales como falta de infraestructura, de recursos, de interés por parte de la administración o por la respuesta incompleta que han dado a sus funciones las Superintendencias y la Junta Central de Contadores (JCC), autoridades de vigilancia definidas en la Ley 1314 , ya que de haberse dado rigurosa observancia a tales funciones, podría garantizarse en mayor medida el cumplimiento y la calidad del proceso dispuesto por Ley para las empresas.

En este sentido, la problemática actual sitúa la necesidad de identificar las causas que han conllevado a que las empresas catalogadas como MIPYMES no hayan cumplido a satisfacción la implementación de las NIIF, centrando la atención en una de las que podría generar un mayor impacto al tener un sustento legal, ya que por Ley se definieron las autoridades de vigilancia y sus respectivas funciones con el fin que el proceso se cumpliera a cabalidad y partiendo de la existencia legal de dichas obligaciones se supondría un proceso cumplido satisfactoriamente.

A partir de las falencias identificadas y las soluciones propuestas, será posible que las autoridades competentes tomen medidas pertinentes en pro de mejorar la infraestructura contable del país. Además, con los resultados obtenidos de este trabajo es menester contribuir al desarrollo de los análisis que se han realizado frente al complejo proceso de implementación de las NIIF en Colombia, específicamente en las MIPYMES, enfocando su objeto de estudio en la incidencia que han tenido las autoridades de vigilancia en éstas, pues en materia contable, se han desarrollado diversos estudios acerca de los impactos, importancia, etapas, entre otros, del proceso de implementación; sin embargo, ha existido escaso interés respecto al papel que han debido jugar en dicho proceso las autoridades de vigilancia definidas en la Ley 1314 desde su entrada en vigencia en el año 2009.

\section{Metodología de investigación}

La investigación es de tipo cualitativo y de carácter explicativo, puesto que centra su atención en las consecuencias que se derivan de lo establecido en la Ley 1314 de 2009 respecto al papel que fue asignado a las autoridades de vigilancia, es decir, se caracterizan las acciones que éstas han tomado para ejercer íntegramente sus funciones, específicamente en lo que refiere a las MIPYMES, al ser dichas autoridades las encargadas de vigilar que se esté llevando a cabo el debido proceso de implementación de estándares internacionales de información financiera en Colombia. Para el logro de lo anterior, se aplicaron instrumentos relacionados con el análisis documental, entrevistas y encuestas.

En lo que se refiere a la investigación documental, se realizó análisis detallado de información e interpretación de contenido, tanto de informes 
publicados por la Junta Central de Contadores y la Superintendencia de Sociedades, como de artículos relacionados con el objeto de estudio, extraídos de revistas que cuentan con gran aceptación en el medio.

En cuanto a las entrevistas, se tomó una muestra intencionada en la que se efectuaron 6 entrevistas a personas que guardan relación directa con las autoridades de vigilancia, expertas en el proceso de convergencia a NIIF en Colombia y altamente reconocidas en el ámbito contable, que actualmente son funcionarios de entidades como la Junta Central de Contadores, el Consejo Técnico de la Contaduría Pública, la Contaduría General de la Nación, entre otros. Para la presentación de la información producto de las entrevistas, se identificaron las principales afirmaciones de los entrevistados, las cuales se referenciarán a lo largo del artículo y servirán de apoyo para las consideraciones incluidas en el mismo.

Finalmente, se realizaron encuestas a contadores públicos con experiencia de al menos un año en implementación de las NIIF, que pertenecieran a MIPYMES y que fueran de la ciudad de Medellín, lo cual corresponde a una población desconocida dada la imposibilidad de determinar la misma. En este sentido, para definir la muestra se tomó un nivel de confianza de $96 \%$ y un margen de error de $7 \%$ aplicados a la siguiente fórmula:

$$
\mathrm{n}=\frac{\mathrm{z}^{2} \times \mathrm{p} \times \mathrm{q}}{\mathrm{e}^{2}}
$$

donde $Z$ es el nivel de confianza

$p$ es la probabilidad de éxito

$q$ es la probabilidad de fracaso

$e$ es el error

$n$ es la muestra.

Reemplazando los valores:

$$
196=\frac{(1,96)^{2} \times 0,5 \times 0,5}{(0,07)^{2}}
$$

De las 196 encuestas que arrojaron como resultado la muestra, se realizaron un total de 116, dando la claridad que los resultados obtenidos son aplicables al $60 \%$ de la población tomada. Dichas encuestas, se realizaron en aras de conocer la percepción de contadores públicos con experticia en el tema acerca del papel desempeñado por las autoridades de vigilancia a lo largo del proceso de convergencia, a partir de preguntas enfocadas en las funciones definidas para éstas en las disposiciones normativas. Los resultados fueron analizados 
Botero, A.; Marulanda, C.; Alvarez, M.; Muñoz, L. Proceso de implementación de las NIIF...

haciendo uso de fórmulas probabilísticas que permitieran resumir, explicitar y concluir la información en datos más claros y dicientes.

\section{Improvisación desde la planeación}

El avance a pasos agigantados que viene atravesando la economía a nivel mundial ha impactado los diferentes procesos que se desarrollan en las empresas de cada país, creando necesidades cuya satisfacción ha debido darse al ritmo acelerado que se presentan para hacerse partícipes de la globalización y no sufrir las consecuencias del aislamiento de su mercado. Un claro ejemplo de ello, es el proceso que refiere a la comunicación eficiente entre las empresas, lo cual exige de éstas la presentación de información financiera homogénea y transparente que dé cuenta de las mejores prácticas contables, para evitar las crisis y las fallas en los mercados, propiciar la integración de los mismos y alcanzar una mayor estabilidad económica.

Es así como se da el surgimiento de las Normas Internacionales de Contabilidad (NIC), posteriormente denominadas Normas Internacionales de Información Financiera (NIIF), emitidas las primeras por el Comité Internacional de Normas Contables y las segundas por el Consejo de Estándares Internacionales de Contabilidad (IASC e IASB respectivamente, por sus siglas en inglés). En un principio, tales normas eran de aplicación voluntaria por las empresas al elaborar sus estados financieros, convirtiéndose años más tarde en un conjunto de estándares globales de forzoso cumplimiento, de alta calidad y comprensibles para los usuarios al tomar sus decisiones económicas, quedando en manos de las autoridades de regulación y vigilancia de cada país la responsabilidad de incluir los estándares en su normatividad y verificar el debido cumplimiento de los mismos, denotando el papel relevante que éstas debieron jugar antes, durante y después del proceso de adopción del nuevo marco normativo.

En Colombia, la Ley 43 de 1990, por la cual se reglamenta la profesión del Contador Público, y el Decreto 2649 de 1993 que, en concordancia con la mencionada Ley, reglamenta la contabilidad en general y establece los principios o normas de contabilidad generalmente aceptados, han constituido el marco legal contable durante más de 15 años y son los antecedentes más cercanos de los mencionados estándares, seguido de la Ley de Reestructuración Empresarial de 1999, en la cual el Gobierno obligó a la revisión de las normas de contabilidad para ajustarlas a los parámetros internacionales.

La obsolescencia de los principios de contabilidad generalmente aceptados y la urgencia de dinamizar el mercado nacional concluyen en el proyecto de Ley 165 de 2007 que dio origen a la Ley 1314 de 2009, principal referente y detonante del proceso de convergencia a Estándares Internacionales de Información Financiera en Colombia. Dicha Ley define, entre otras cosas, 
los objetivos del proceso de convergencia, la independencia de las normas tributarias frente a las contables, la regulación contable a la cual deben acogerse tanto personas naturales y jurídicas obligadas a llevar contabilidad, como las personas encargadas de la preparación, promulgación y aseguramiento de información financiera y las autoridades competentes en materia de normalización, regulación y vigilancia (Álvarez \& Muñoz, 2014).

El propósito principal que atañe el proceso de convergencia se enmarca en la necesidad de los stakeholders de obtener información acorde a sus intereses, permitiéndoles tomar decisiones más acertadas, evitando asimismo situaciones que a raíz de información financiera que no refleje la realidad de las empresas lleguen a concluir en cuantiosos fraudes y estafas. En este sentido, era menester que las autoridades colombianas fuesen conscientes de las exigencias que traía consigo la implementación de estándares internacionales, realizando como punto de partida estudios rigurosos de las necesidades de información que tienen los usuarios de los diferentes tipos de empresas colombianas (Casinelli, 2013).

En efecto, la planificación debe ser vista como un proceso inherente a la aplicación de un nuevo marco normativo, incluso más importante que la regulación en sí misma, en cuanto brinda trazabilidad a las diferentes etapas que deben surtirse por parte, en un principio, de las autoridades $\mathrm{y}$, posteriormente, de las empresas. Hablar de planificación frente a los procesos regulatorios implica considerar estudios investigativos previos, los cuales ciertamente no fueron surtidos por las autoridades colombianas competentes, tales como los impactos financieros en las empresas, los costos de implementación, los impactos sobre finanzas públicas, la disponibilidad de recursos, los sistemas de información y los profesionales idóneos.

Según expresa Machado:

Cuando se habla de regulación sin atender procesos previos de reflexión, evaluación y acuerdo, se decide por un camino sin regreso donde las imposiciones y la improvisación, son el designio metodológico para "resolver" un problema complejo que involucra diversos intereses. (2015, p. 54)

Lo anterior, permite inferir que la inejecución de la etapa de planificación o su realización inconclusa conlleva a una normativa sin sustentos técnicos claros, lo cual para el caso de Colombia, es una postura válida al considerar que se repitió una vez más lo que se ha venido dando históricamente en el país, en un momento que era propicio para cambiar la tradición de emitir regulaciones de imprevisto y de manera impositiva, ya que fue más importante la emisión de conceptos normativos, que el análisis de los estudios previos anteriormente mencionados y las condiciones específicas del sistema económico y empresarial local, siendo una situación crucial que muchas de las pequeñas y medianas 
Botero, A.; Marulanda, C.; Alvarez, M.; Muñoz, L. Proceso de implementación de las NIIF...

empresas que se encontraban obligadas a llevar contabilidad, no lo hacían o lo hacían de manera informal bajo la anterior normatividad, lo cual significaba un proceso de formalización y aplicación de las NIIF significativamente traumático.

Las anteriores circunstancias dan cuenta que el proceso de convergencia hacia estándares internacionales en Colombia ha estado inmerso desde sus inicios en un cúmulo de falencias por parte de las autoridades, el cual era difícil de resarcir antes de la entrada en vigencia de las NIIF, teniendo en cuenta las deficiencias que ya eran propias del sistema regulatorio, entre las cuales destacan la diversidad incoherente de normas y de reguladores, el ámbito legal por encima del económico, un vínculo entre el costo-beneficio altamente desproporcionado y una emisión de normas en los tiempos que no corresponden con los desafíos financieros. Las mencionadas debilidades manifiestan el disperso y anacrónico sistema regulatorio contable existente en Colombia que no pudo ser intervenido ni mejorado al menos por el Consejo Técnico de la Contaduría Pública (CTCP), autoridad de regulación y normalización técnica, dada su poca influencia en la organización gubernamental, al encontrarse en menor rango que las superintendencias, las cuales han asumido el rol de reguladores, interpretadoras y orientadoras de marcos conceptuales y procedimentales (CTCP, 2004).

Es así como se evidencia la improvisación del marco legal colombiano, en el cual son poco identificables las prácticas que son ejercidas por cada autoridad, conllevando a la ejecución de funciones ajenas a su naturaleza, la omisión de acciones necesarias para dar respuesta a sus obligaciones o la falta de potestad frente a los organismos de mayor rango para presentar las falencias que se derivan de su funcionamiento.

\section{La dispersa coordinación en el sistema regulatorio contable}

Si bien la Ley 1314 fue acertada en su momento, ha cimentado las bases para que Colombia lleve a cabo el proceso de convergencia a estándares internacionales en toda su dimensión y logró dar directrices concretas que ponían de manifiesto la capacidad de las diferentes autoridades para incorporar en las empresas colombianas un nuevo marco normativo contable bajo estándares internacionales, fueron muchas las responsabilidades que quedaron consignadas en el papel y los roles que debieron asumirse con prontitud y rectitud por cada uno de los actores de este proceso para que pudiera surtirse acorde a lo establecido. Adoptar las NIIF en Colombia para cumplir los objetivos que de ellas se derivan, suponía un reto que implicaba cambios y esfuerzos significativos, que de no realizarse conllevaría a un proceso insatisfecho e inconcluso.

Es así como los organismos reguladores cumplen una función trascendental en el adecuado funcionamiento de los sistemas de cualquier índole, sin 
embargo, es indispensable diferenciar los roles que cada uno desempeña dentro del sistema, su alcance y la interrelación que tienen entre sí (Colmenares, 2011). En Colombia, al considerar las entidades de regulación que integran el sistema contable, se identifican una multiplicidad de autoridades que terminan por ocasionar confusión frente a los parámetros que fundamentan la contabilidad en sí y por distorsionar los propósitos de la información que debe ser presentada por las empresas a los usuarios.

La mencionada problemática pretendió atenderse mediante la coordinación entre las entidades públicas definidas en el artículo 12 de la Ley 1314 con el propósito que las normas de quienes participan en un mismo sector económico fuesen homogéneas, consistentes y comparables. Dicha coordinación quedó en cabeza del Comité Intersectorial instaurado mediante el Decreto 3048 de 2011 a quien, además, se le encargó la función de emitir recomendaciones sobre la expedición de instrucciones y reglamentaciones a las autoridades de regulación y de supervisión en los términos de la Ley 1314 del 2009 (Decreto 3048, 2011, art. 4). Por ende, el Comité puede verse como un mecanismo que, de ejecutar sus funciones acordes a lo establecido, hubiera significado un valor agregado al proceso de convergencia, pero hasta qué punto lo hizo y qué impacto generó es un interrogante que requiere ser resuelto.

El Comité Intersectorial es un instrumento que facilitaría en gran medida la comunicación entre las diferentes entidades de regulación, normalización y supervisión, en aras que se pudieran dar a conocer de manera oportuna y solventar conjuntamente los problemas que se fueran presentando. Sin embargo, es cuestionable la poca relevancia que ha tenido dicho mecanismo frente a la que ha debido tener, puesto que es escasa la información que puede encontrarse en los diferentes medios acerca del papel que se ha desempeñado por parte de las entidades integrantes del Comité.

Lo anterior tiene una razón de ser, tal como alude Wilmar Franco Franco ${ }^{1}$ (Comunicación personal, 28 de agosto de 2017), Presidente del Consejo Técnico de la Contaduría Pública: "el Comité Intersectorial puede no haber sido efectivo debido a la independencia de cada una de las entidades que lo conforman", lo cual influye de manera negativa en la funcionalidad del Comité, puesto que éste no tiene la estructura suficiente para tomar decisiones que afecten a las entidades que lo integran. Por lo tanto, el proceso de implementación no ha tenido un organismo efectivo de coordinación entre entidades, que resulta fundamental y más en un país como Colombia, donde las funciones están

1 Contador público. Se desempeñó como Gerente de Consultoría en Baker Tilly Colombia en el área de NIIF. También trabajó como asesor especialista del Instituto de Promoción Industrial en las áreas de crédito, deuda, contabilidad de valores, auditoría financiera y gestión de riesgos. Editor de varias publicaciones de contabilidad y leyes tributarias, entre ellas "El ABC de las NIIF y Guía para la aplicación por primera vez de las NIIF”. 
Botero, A.; Marulanda, C.; Alvarez, M.; Muñoz, L. Proceso de implementación de las NIIF...

distribuidas en las diferentes entidades y cada una de ellas puede ser muy eficiente en el cumplimiento de las mismas, pero en su conjunto no generan un valor agregado, conllevando a que no se tenga una infraestructura sólida y se generen dificultades en los procesos.

La nula independencia de los organismos que rigen la contabilidad en Colombia, como son el Ministerio de Hacienda y Crédito Público, el Consejo Técnico de la Contaduría Pública y la Junta Central de Contadores, al formar parte vinculante del Estado, desembocaría en un proyecto de ley a puerta cerrada para entes que pudieron constituir una mirada más amplia acerca de los impactos que generaría la aplicación de las normas internacionales. Las universidades, gremios profesionales y las entidades privadas no tuvieron la participación continua y necesaria en el proyecto, ni en la definición e investigación de estudios previos, lo cual reflejó un producto demarcado por el interés del gobierno en la imposición de normas por el mero hecho de cumplir con los requisitos legales y de cumplir con las necesidades que apremiaba el mundo financiero internacional (Ferrer, 2013).

Así pues, las Superintendencias y la JCC, autoridades de supervisión y de vigilancia definidas en la Ley 1314 para la puesta en marcha de los estándares internacionales en Colombia, fueron las principales responsables de velar por el cumplimiento de la normatividad contable vigente y sobre ellas recayó, en gran medida, la definición e implantación de las acciones necesarias para que las empresas actuasen en concordancia con los parámetros establecidos en la Ley. Respecto a las Superintendencias, este artículo se centra en la Superintendencia de Sociedades debido al papel trascendental y de liderazgo que ha jugado a lo largo del proceso de convergencia, además del cubrimiento significativo de entidades que sobre ella recae.

Es indiscutible que el cumplimiento de la función de supervisión y de vigilancia, tanto por parte de la Superintendencia de Sociedades como de la JCC, se vio afectado por una serie de aspectos de diversa índole, que van desde el carácter histórico de tales organismos y la planificación de los procesos de vigilancia, hasta las medidas tomadas a partir de la aplicación de la Ley 1314 que no respondían a las necesidades existentes. Asimismo, por la falta de infraestructura, de recursos y de planes de acción por parte de dichas autoridades para ejercer sus funciones sobre la multiplicidad de entidades que componen el sistema colombiano y la gran cantidad de contadores que en él ejercen.

Respecto a la multiplicidad de entidades es menester indicar que este estudio se enfoca en la función desempeñada por la Superintendencia de Sociedades sobre las MIPYMES, las cuales son catalogadas como microempresas, pequeñas y medianas empresas, según la definición de las empresas en Colombia expresada en la Ley 590 de 2000, modificada por la Ley 905 de 2004, la cual se detalla en el siguiente gráfico: 
Ilustración 1. Clasificación de las empresas en Colombia.
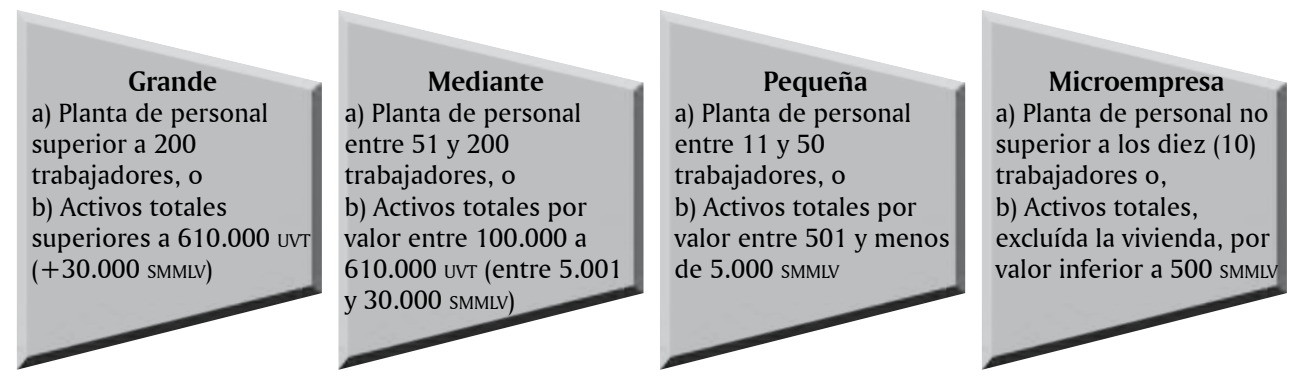

Fuente: Elaboración propia

Con base en la categorización detallada en el gráfico anterior, tras la puesta en marcha de la Ley 1314, el CTCP publicó el Documento de Direccionamiento Estratégico, mediante el cual se definieron los tres grupos de empresas que debían aplicar el nuevo marco normativo de convergencia a NIIF. Por tanto, las empresas grandes, medianas, pequeñas y microempresas fueron clasificadas en los Grupos I, II y III, tal como se muestra en el siguiente gráfico (Decreto 2420, 2015):

Ilustración 2. Definición de grupos bajo NIIF.

\begin{tabular}{|c|c|c|}
\hline Grupo I & Grupo II & Grupo III \\
\hline $\begin{array}{l}\text { a) Emisores de valores; } \\
\text { b) Entidades de interés público; } \\
\text { c) Entidades que tengan Activos totales } \\
\text { superiores a treinta mil ( } 30.000) \\
\text { SMMLV o planta de personal superior } \\
\text { a doscientos (200) trabajadores; que no } \\
\text { sean emisores de valores ni entidades de } \\
\text { interés público y que cumplan además } \\
\text { cualquiera de los siguientes requisitos: } \\
\text { i. ser subordinada o sucursal de una } \\
\text { compañía extranjera que aplique NIIF; } \\
\text { ii. ser subordinada o matriz de una } \\
\text { compañía nacional que deba aplicar NIIF; } \\
\text { iii. realizar importaciones (pagos al } \\
\text { exterior, si se trata de una empresa de } \\
\text { servicios) o exportaciones (ingresos } \\
\text { del exterior, si se trata de una empresa } \\
\text { de servicios) que representen más } \\
\text { del 50\% de las compras (gastos y } \\
\text { costos, si se trata de una empresa de } \\
\text { servicios) o de las ventas (ingresos, } \\
\text { si se trata de una compañía de } \\
\text { servicios), respectivamente, del año } \\
\text { inmediatamente anterior al ejercicio } \\
\text { sobre el que se informa, o } \\
\text { iv. ser matriz, asociada o negocio } \\
\text { conjunto de una o más entidades } \\
\text { extranjeras que apliquen NIIF. }\end{array}$ & $\begin{array}{l}\text { a) Empresas que no cumplan con los } \\
\text { requisitos del literal c) del Grupo I; } \\
\text { b) Empresas que tengan Activos } \\
\text { totales por valor entre quinientos } \\
\text { (500) y treinta mil (30.000) SMMLV } \\
\text { o planta de personal entre once (11) } \\
\text { y doscientos (200) trabajadores, y } \\
\text { que no sean emisores de valores ni } \\
\text { entidades de interés público; y } \\
\text { c) Microempresas que tengan } \\
\text { Activos totales excluida la } \\
\text { vivienda por un valor máximo } \\
\text { de quinientos (500) SMMLV o } \\
\text { Planta de personal no superior } \\
\text { a los diez (10) trabajadores, y } \\
\text { cuyos ingresos brutos anuales } \\
\text { sean iguales o superiores a } 6.000 \\
\text { SMMLV. Dichos ingresos brutos } \\
\text { son los ingresos correspondientes } \\
\text { al año inmediatamente anterior } \\
\text { al periodo sobre el que se } \\
\text { informa. Para la clasificación de } \\
\text { aquellas empresas que presenten } \\
\text { combinaciones de parámetros de } \\
\text { planta de personal yactivos totales } \\
\text { diferentes a los indicados, el factor } \\
\text { determinante para dicho efecto, } \\
\text { será el de activos totales. }\end{array}$ & $\begin{array}{l}\text { (a) Personas naturales o } \\
\text { jurídicas que cumplan } \\
\text { los criterios establecidos } \\
\text { en el art. 499 del } \\
\text { Estatuto Tributario (ET) } \\
\text { y normas posteriores } \\
\text { que lo modifiquen. Para } \\
\text { el efecto, se tomará el } \\
\text { equivalente a UVT, en } \\
\text { salarios mínimos legales } \\
\text { vigentes. } \\
\text { (b) Microempresas que } \\
\text { tengan Activos totales } \\
\text { excluida la vivienda por } \\
\text { un valor máximo de } \\
\text { quinientos (500) SMMLV } \\
\text { o Planta de personal } \\
\text { no superior a los diez } \\
\text { (10) trabajadores que } \\
\text { no cumplan con los } \\
\text { requisitos para ser } \\
\text { incluidas en el Grupo II ni } \\
\text { en el literal anterior. }\end{array}$ \\
\hline
\end{tabular}

Fuente: tomado del Direccionamiento Estratégico del CTCP, del 5 de diciembre de 2012. 
Botero, A.; Marulanda, C.; Alvarez, M.; Muñoz, L. Proceso de implementación de las NIIF...

En efecto, según las directrices dadas por el CTCP para cada uno de los grupos definidos, las empresas tenían la responsabilidad de aplicar el nuevo marco normativo en los tiempos y términos establecidos, mientras que las autoridades de vigilancia, en aras de propiciar el cumplimiento por parte de las empresas, debían expedir guías e instructivos y, posteriormente, velar por la debida ejecución de dicho marco normativo. No obstante, la vigilancia por parte de la Superintendencia de Sociedades de las entidades que quedaron catalogadas dentro de los Grupos II y III, ha sido un proceso complejo, satisfecho en ciertos aspectos e inconcluso en otros, debido principalmente al número significativo de entidades que los conforman, al representar las MIPYMES el 99\% de las empresas del país, tal como se ilustra en el siguiente gráfico.

Ilustración 3. Número de empresas por tamaño

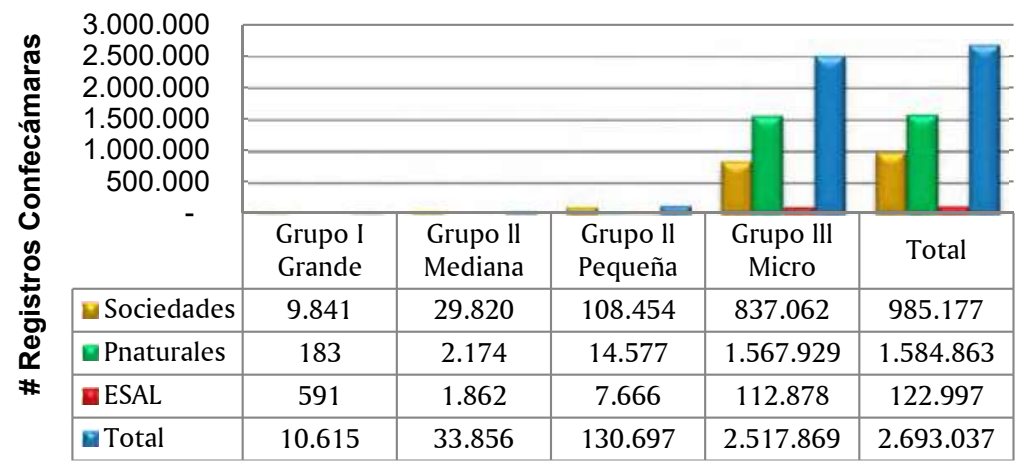

Fuente: adaptado de Primer Seminario Internacional Contable, Franco (2017), que tomó de Confecámaras, Datos Consultados el 7 de febrero de 2017.

Tal como se evidencia en el esquema anterior, la totalidad de empresas colombianas es una cifra bastante alta, respecto a las facultades de las autoridades de vigilancia para abordarlas eficazmente. Además, de las 2.693.037 entidades que componen el sistema empresarial colombiano, 2.517.869 son microempresas, cifra equivalente a un 93.5\%, es decir, Grupo III en su mayoría. No obstante, es menester aludir que no todos los registros se encuentran activos, dado que un gran porcentaje pertenece a entidades que no renuevan su matrícula mercantil.

Es importante indicar, que si bien es cierto que el Grupo III ha sido el Grupo más desatendido por las autoridades de control en el acompañamiento y vigilancia en el cumplimiento de la Ley 1314 de 2009, las empresas que lo conforman deben aplicar el Decreto 2706 de 2012, conocido como el Decreto de la Contabilidad Simplificada, el cual aunque se desarrolló teniendo en cuenta la normatividad NIIF, presenta grandes diferencias a estos estándares y simplifica 
sustancialmente el manejo de los diferentes elementos de los estados financieros, los cuales incluso se reducen a dos, por lo tanto aunque existió y existe un abandono por parte de las entidades de control, al no darle importancia a este Grupo dado que no se emitieron guías ni conceptos que permitieran clarificar los conceptos aplicables a este Grupo, es claro que la exigencia establecida en el Decreto citado es menor en relación con los Grupos I y II.

\section{La débil estructura de las autoridades de vigilancia}

La Junta Central de Contadores de la mano de las superintendencias se reconocen por su función de vigilancia, estando la primera enfocada a los profesionales que ejercen la disciplina contable, mientras que las segundas a las empresas obligadas a presentar información financiera. Si bien ambas entidades funcionan como autoridades de vigilancia, cada una de ellas tiene una estructura diferente, la cual es un punto de partida trascendental para caracterizar el papel que han jugado frente al proceso de convergencia.

De una parte, la JCC es una Unidad Administrativa Especial con personería jurídica, adscrita al Ministerio de Comercio, Industria y Turismo, que se divide en dos componentes esenciales: la Dirección General y el Tribunal Disciplinario, representados cada uno de ellos por el Director General y el Presidente del Tribunal, respectivamente. El Tribunal Disciplinario tiene la función de actuar, como su nombre lo indica, como autoridad disciplinaria de la profesión contable, mientras que la Dirección General tiene a su cargo las funciones de registro e inspección y vigilancia, asimismo de ser en cabeza del Director General, responsable de disponer y ejecutar el presupuesto, tanto para su dirección como para el Tribunal Disciplinario, afectando directamente las funciones que son llevadas a cabo por este último, quien indudablemente, no posee unos dientes fuertes para manejar el proceso disciplinario.

El proceso disciplinario puede iniciar de tres formas: por queja, la cual es impuesta por cualquier persona bien sea natural o jurídica; por informe, derivado de entidades del Estado; y de oficio, por orden del Tribunal Disciplinario, producto de advertencias de un hecho irregular por información de prensa, radio, entre otros. En este sentido, la JCC se ha enfocado esencialmente en investigar los procesos que llegan a su escritorio por cualquiera de las formas anteriormente descritas, pero en los momentos que el gremio contable espera un papel más protagónico de la entidad, ésta se queda corta, pues no cuenta con la capacidad de investigar e indagar procesos que surjan desde la misma entidad. Tal como afirma Oscar Torres Mendoza ${ }^{2}$, la JCC se ha dedicado principalmente a la sanción de los contadores,

2 Contador Público y Especialista en Administración y Auditoria Tributaria de la Universidad Jorge Tadeo Lozano. Participante por Colombia en curso IFRS para PYMES "Train the Trainers" dictado por IASB en Panamá. Socio Fundador de AMERICA ADVISING \& AUDITING SERVICES 
Botero, A.; Marulanda, C.; Alvarez, M.; Muñoz, L. Proceso de implementación de las NIIF...

mas no se ha esmerado por dotarse de una actitud proactiva para iniciar los procesos disciplinarios por sus mismos medios (Comunicación personal, 29 de septiembre de 2017).

Los procesos que llegan al Tribunal Disciplinario, actualmente son estudiados, organizados e investigados en todo lo concerniente al debido proceso por abogados y contadores de planta, en su mayoría por los primeros, que en muchos casos no conocen suficientemente de derecho contable o, en su defecto, no tienen ninguna experiencia en el tema, lo que demuestra que en muchos casos no se cuenta con el personal idóneo para ejercer una función tan importante como ésta. Posteriormente, cada expediente es asignado a uno de los siete funcionarios principales que conforman el Tribunal Disciplinario, el cual sesiona cada 15 días con el fin de que cada funcionario exponga los procesos analizados. Lo anterior, a razón que ellos no son de tiempo completo, esto sin contar, que tampoco tienen una retribución salarial por sus labores, lo cual indica que los pocos miembros con los que cuenta el Tribunal para revisar dichos procesos, no están abocados de lleno en estas labores.

A los miembros del Tribunal Disciplinario que viven fuera de la ciudad les pagan viáticos a fin que sesionen, sin obtener alguna otra retribución monetaria, ellos lo hacen meramente por la profesión contable, mientras que el director general, ejecuta los dineros en otros temas, que tal vez pudieran o no ser trascendentales, pero que indudablemente están dejando al Tribunal Disciplinario carente de una estructura fuerte para ejecutar sus funciones debidamente (H. Bermúdez, comunicación personal, 29 de septiembre de 2017).

Aunado a lo anterior, en el Simposio XVI de Contaduría Pública de la Universidad de Antioquia, el presidente del Tribunal Disciplinario, afirmó que en el momento existen alrededor de 1.400 investigaciones en proceso, las cuales deben ser respondidas por los 7 funcionarios que hacen parte de éste, lo que equivale a decir que a cada funcionario corresponden 200 casos, cifra extremadamente alta al momento de considerar que su función en el Tribunal no es de tiempo completo, razón por la cual, en muchos procesos puede darse el caso que los expedientes se venzan por falta de funcionarios. Adicional a ello, en una encuesta realizada a contadores expertos en el tema de NIIF, cuando estos fueron preguntados en un grado de 1 a 5 , siendo 1 la menor calificación y 5 la mayor, si consideraban que la JCC posee personal suficiente para responder a las funciones que tenía a cargo, el $54 \%$ indicó el grado 1 y 2 , y tan solo el $7 \%$ indicó el grado 4 y 5, lo cual vislumbra la percepción de los profesionales contables de la insuficiencia de personal por parte de esta entidad.

AAAS Ltda. Responsable de Servicios de Revisoría Fiscal, Auditoria, Asesoría Tributaria de clientes de diferentes industrias y tamaños. Conferencista en variados temas, tales como auditoría forense, tributación, NIIF y conversión de EEFF. 
Además, una de las críticas más generalizadas y popularizas es que la JCC no actúe solo como autoridad sancionatoria, sino también de prevención, pues se ha dedicado en gran medida al registro y expedición de tarjetas profesionales, olvidando y dejando a un lado las funciones que le han sido atribuidas, en las cuales el tema sancionatorio y el seguimiento de las competencias profesionales, se torna un tema fundamental para que la profesión contable se sienta vigilada y respaldada por este organismo. Tal y como expresa el CTCP:

La JCC se ha dedicado a ejercer su función disciplinaria, pero particularmente ha dejado relegada la función de supervisión de la profesión y de actuación como órgano preventivo, limitándose a autorizar el registro, pero no el seguimiento de competencias profesionales. (2004, p. 128)

Por otra parte, la Superintendencia de Sociedades es un organismo técnico, adscrito al Ministerio de Comercio, Industria y Turismo, con personería jurídica, autonomía administrativa y patrimonio propio, mediante el cual el Presidente de la República ejerce inspección, vigilancia y control de las sociedades mercantiles, así como las facultades que le señala la ley en relación con otros entes, personas jurídicas y personas naturales, según lo establece el artículo $1^{\circ}$ del Decreto 1023 de 2012. Sus funciones principales se describen de la siguiente manera (Ley 222, 1995, arts. 83-84-85):

La inspección se trata de un seguimiento ocasional, por medio del cual esta entidad puede solicitar información a cualquier sociedad comercial no vigilada por la Superintendencia Financiera de Colombia. Es el grado de fiscalización más leve que ejerce la Superintendencia.

La vigilancia radica en una fiscalización de carácter permanente por medio de la cual la Superintendencia de Sociedades busca que esas sociedades en su formación y funcionamiento se ajusten a la ley a y los estatutos. Mediante éste ejerce facultades de mayor alcance que las de inspección.

El control se deriva como el grado más intenso de fiscalización, el cual se ejerce sobre una sociedad que afronte una situación crítica de orden jurídico, económico y administrativo. La Superintendencia de Sociedades podrá ordenar a cualquier sociedad comercial no vigilada por otra superintendencia, la adopción de mecanismos que subsanen situaciones críticas de orden jurídico, contable, administrativo.

Son sociedades inspeccionadas, todas las entidades comerciales que no se encuentren vigiladas por Superintendencia Financiera; vigiladas cuando presentan alguna de las causales previstas en el capítulo 1 del título 2 del libro 2 del Decreto 1074 de 2015; y, controladas, cuando por acto administrativo de carácter particular presentan alguna de las situaciones señaladas en el artículo 85 de la Ley 222 de 1995. 
Botero, A.; Marulanda, C.; Alvarez, M.; Muñoz, L. Proceso de implementación de las NIIF...

La Superintendencia de Sociedades es encabezada por el Despacho del Superintendente de Sociedades, el cual es apoyado por tres oficinas asesoras. Asimismo, del Despacho se desprenden 4 Delegaturas y 1 Secretaría, siendo de importancia para el tema que se está abordando, el rol que cumplen la Delegatura de Asuntos Económicos y Contables y la Delegatura para Inspección, Vigilancia y Control.

La Delegatura de Asuntos Económicos y Contables tiene asignadas las funciones de ordenar, dirigir y coordinar la solicitud de información financiera a las entidades obligadas a remitirla; sancionar a las entidades que sin justificación omitan el cumplimiento del envío de la información financiera; y, ordenar la rectificación de los estados financieros o las notas que no se ajusten a las normas legales, según los incisos 3,4 y 13, respectivamente, del artículo 13 del Decreto 1023 de 2012. De otro lado, la Delegatura para Inspección, Vigilancia y Control, tiene la función de ejercer inspección, vigilancia y control sobre las sociedades comerciales, sucursales de sociedad extranjera, empresas unipersonales y cualquier otro sujeto que determine la ley, para lo cual dirigirá y coordinará las actuaciones administrativas necesarias para el cumplimiento de estas atribuciones, de acuerdo a lo indicado en el inciso 4 del artículo 14 del Decreto en mención (Decreto 1023, 2012, arts. 13-14).

A partir de la entrada en vigencia de la Ley 1314 y de la definición de los tres grupos de entidades que debían aplicar las NIIF en Colombia, la Superintendencia de Sociedades ha solicitado a las sociedades comerciales, sucursales de sociedades extranjeras y empresas unipersonales, por medio de circulares externas, los estados financieros y los documentos adicionales dando aplicación al nuevo marco normativo contable, especificando la obligatoriedad del reporte por parte de las entidades empresariales sometidas a su vigilancia y control, así como de las entidades sometidas a inspección que les sea impartida la respectiva orden.

Así mismo, las funciones delegadas a la Superintendencia de Sociedades respecto a la emisión de guías en materia de contabilidad empezaron a ser ejercidas mediante herramientas tales como talleres y guías de aplicación para las empresas de los tres grupos, poniendo de manifiesto los avances logrados por esta entidad frente a la implementación del nuevo marco normativo. Sin embargo, las autoridades se han limitado a hacer recomendaciones de carácter general y emitir conceptos, dejando a un lado su principal función, la cual demanda más compromiso frente al acompañamiento que se le debe dar a las empresas para realizar un proceso efectivo de vigilancia (Mantilla, 2017).

\section{VI.Críticas del informe rosc no contempladas por la ley 1314}

El funcionamiento de las autoridades de vigilancia de la profesión contable anteriormente descritas, fueron objeto de modificación en el anteproyecto 
de la Ley 1314 de 2009, dado que se concibió inviable que la JCC con su limitada estructura pudiese afrontar la gran responsabilidad que implicaba la implementación de un nuevo marco normativo. Pensamiento que se encuentra muy alineado con las críticas realizadas por el Banco Mundial en el Report on the Observance of Standards and Codes (ROSC), estudio aplicable a los países con el fin de mejorar la calidad de la información financiera y la calidad de la profesión contable, en el cual se afirma que:

La JCC mantiene un registro de contadores públicos y tiene el poder para imponer las sanciones a los contadores públicos registrados que infrinjan las disposiciones. Sin embargo, en la práctica, este cuerpo no tiene un mecanismo para supervisar y dar fuerza al ejercicio de la profesión y para la determinación de requisitos para su ejercicio. (...) La JCC carece de presupuesto suficiente para realizar las actividades para las cuales la ley le determina competencia. (2005, p. 5)

A raíz de las falencias anteriormente mencionadas, las funciones de la JCC planeaban dejarse en manos de la Superintendencia de Sociedades, lo que hubiese significado una transformación de fondo a las autoridades de vigilancia, puesto que se hubiera establecido un único organismo encargado de velar por el cumplimiento de las normas contables aplicables.

Considerar que las funciones realizadas por la JCC fueran asignadas a una dependencia de la Superintendencia de Sociedades, es decir, que una unidad administrativa especial creada con la finalidad de ejecutar un programa específico fuese reemplazada por una sección de un organismo técnico, pone de manifiesto la incapacidad del legislador para dimensionar la necesidad de un cambio radical que garantizara el cumplimiento de los estándares internacionales a cabalidad. En efecto, aunque la supresión de la JCC no hubiera logrado solventar las falencias ligadas al ejercicio de sus funciones, sí resultaba necesaria una transformación inducida al fortalecimiento de dichas falencias, para que pudiese actuar con mayor efectividad y amplitud.

Como se había mencionado, pese a que la supervisión de los contadores es función de la JCC, la supervisión de las entidades obligadas a presentar información financiera es obligación de las Superintendencias, siendo ambas autoridades responsables de velar por la debida ejecución de la normatividad vigente. Estas últimas no fueron objeto importante de discusión en el proyecto que dio lugar a la Ley 1314, excepto por lo que se refirió en párrafos anteriores respecto a la asignación de las funciones de la JCC a la Superintendencia de Sociedades, lo cual podría inducir a pensar que su papel era desempeñado a cabalidad, incluso para considerar la delegación de otras funciones.

No obstante, en el Informe ROSC se refiere que las Superintendencias se enfocan esencialmente en emitir guías y conceptos del campo contable en vez de vigilar su cumplimiento. Además, la Superintendencia de Sociedades posee un departamento especial que revisa los estados financieros, el 
Botero, A.; Marulanda, C.; Alvarez, M.; Muñoz, L. Proceso de implementación de las NIIF...

cual escasamente determina infracciones en los mismos respecto a las normatividades vigentes en materia contable (Banco Mundial, 2005).

Ahora bien, conociendo las modificaciones que se planeaban efectuar a los organismos de vigilancia, es menester indicar que las mismas se quedaron meramente sobre el escritorio y a cambio de ello, en la emisión de la Ley 1314 de 2009 se les atribuyeron funciones muy similares a las que ya tenían bajo su responsabilidad, ignorando todas las falencias que se venían dando.

Así pues, por una parte, a la JCC se le ratificó en el artículo 10 de la Ley en mención, la obligación de vigilancia en términos de la profesión contable que venía desarrollando desde hace más de cincuenta (50) años, ejerciendo como autoridad disciplinaria de la profesión contable, con la potestad de solicitar, inspeccionar y sancionar a quien así lo requiera con el fin de vigilar que las normas referentes al proceso de convergencia sean cumplidas. Añadido a lo anterior, la JCC continúa con las funciones que previamente venía ejecutando conforme a la Ley 43 de 1990, entre las cuales se encuentran las de ejercer la inspección y vigilancia de los contadores públicos y las normas que aplican, el registro de contadores públicos, la expedición de tarjetas profesional y la denuncia ante autoridades competentes a quienes se identifiquen como contadores públicos cuando no lo sean (Ley 43, 1990, art. 20). En efecto, la JCC siguió con las mismas competencias y estructura que venía ejerciendo con respecto a Ley 43.

Por otra parte, a las superintendencias les son asignadas en el artículo 9 de la Ley 1314 las funciones de supervisión, entre las cuales atañe esencialmente velar porque los entes bajo inspección, vigilancia o control, así como sus funcionarios, cumplan con los estándares internacionales de información financiera, aplicar las sanciones pertinentes y expedir normas técnicas especiales en materia contable en los términos fijados con el fin de guiar el proceso (Ley 1314, 2009, art. 9).

Aunado a las funciones de las autoridades de vigilancia, es importante destacar el rol asignado al Consejo Técnico de la Contaduría Pública en el artículo 6 como autoridad de regulación y normalización técnica, el cual dio inicio a las acciones requeridas para la puesta en marcha de la Ley 1314, a través del Documento de Direccionamiento Estratégico, cuyo objetivo era orientar el desarrollo efectivo del proceso de convergencia hacia las normas de contabilidad e información financiera con estándares internacionales. La propuesta de dicho documento fue presentada en tres ocasiones al público interesado para que efectuara sus sugerencias, recomendaciones y aportes, siendo la primera versión expuesta en junio de 2011 y la última en diciembre de 2012, obteniendo un total de 48 comentarios, tal como se detalla en el siguiente gráfico. 
Ilustración 4. Comentarios realizados al Direccionamiento Estratégico por entidades

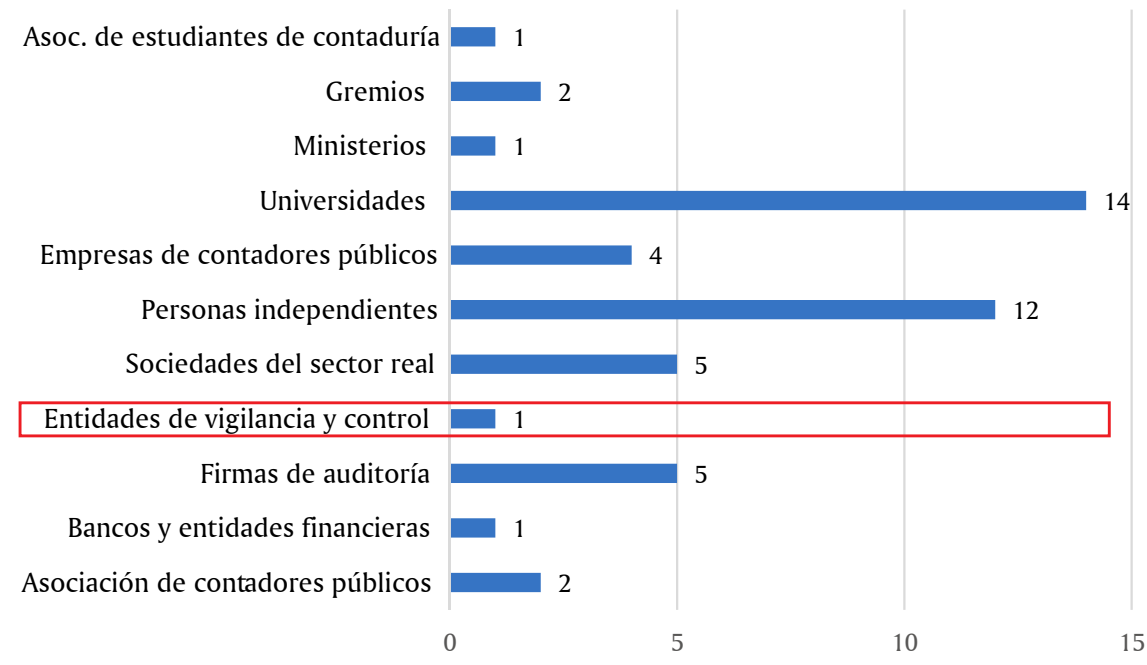

Adaptado de: http://www.comunidadcontable.com/BancoMedios/Documentos\%20PDF/ convergenciaaestandaresinternacionalesdeinformacion.pdf

Del total de 48 comentarios recibidos por el CTCP, solo 1 de ellos fue remitido por las entidades de vigilancia y control, lo cual pone de manifiesto su escasa participación en la definición de un documento cuyo impacto era crucial para el proceso que se deriva de la implementación de las NIIF. Así mismo, es cuestionable la escasa o nula intervención de entidades y organizaciones que deberían haber participado activamente en este proceso, tales como entidades del Estado, distintos gremios como la ANDI y ACOPI, empresas del sector real y financiero, entre otros, puesto que representan sectores y grupos de interés que tienen que ver en forma directa con la información financiera que se debe presentar en los estados financieros de propósito general y cuya participación, con seguridad, hubiese enriquecido la discusión y contribuido a mejorar el proceso de convergencia (López \& Zea, 2011).

\section{Impacto nulo en la junta central de contadores y en el cumplimiento de su rol frente a las NIIF}

Garantizar el adecuado cumplimiento de las funciones asignadas a las diferentes autoridades, fue un objetivo contemplado en la Ley 1314 en su artículo 11, el cual hace referencia a los ajustes institucionales que debía efectuar el Gobierno Nacional, respecto a la conformación, la estructura y el funcionamiento, de la JCC, entre otras entidades. En efecto, al año siguiente de emitida la Ley en mención, se modificó parcialmente la estructura de la JCC, mediante el Decreto 1955, obteniendo como resultado variaciones de tipo 
Botero, A.; Marulanda, C.; Alvarez, M.; Muñoz, L. Proceso de implementación de las NIIF...

jurídico y una nula transformación frente al desarrollo de sus competencias, siendo ésta realmente necesaria para solventar la falta del ejercicio proactivo de supervisión e ir más allá de la mera función de registro y supervisión reactiva.

Ahora bien, es pertinente cuestionar la relación entre las fallas identificadas en el funcionamiento de este organismo y el efecto logrado tras la modificación que se le implementó, resaltando que la finalidad de ésta consistía en que la JCC ejerciera cabalmente sus funciones en virtud de los establecido en la Ley de Convergencia y, por ende, afirmar que la JCC logró solventar sus falencias a raíz de la transformación realizada es arriesgarse a decir que ha podido supervisar el cumplimiento de la aplicación de las NIIF en la práctica profesional, lo cual es un ideal discutible.

Para conocer el resultado obtenido tras la modificación realizada a la JCC se consultó la opinión de varios contables reconocidos del país, quienes expusieron su postura crítica al respecto:

El presidente del Tribunal Disciplinario de la JCC, Luis Eduardo Forero Vargas $^{3}$, indica que la modificación en nada benefició a la JCC, en contraparte, la perjudicó al concentrar el poder burocrático en cabeza de la Dirección, puesto que a la JCC le fue asignada personería jurídica, de manera específica a la Dirección Administrativa, designando al Director General como representante legal y con autonomía para el manejo del gasto, restando funciones al Tribunal Disciplinario, lo cual ha generado un conflicto al interior de la entidad, al no existir certidumbre frente a las funciones del Tribunal y de la Dirección Administrativa (Comunicación personal, 29 de septiembre de 2017).

El Contador General de la Nación, Pedro Luis Bohórquez Ramírez 4 , afirma que los cambios quedaron en el papel y la modificación no surtió algún impacto, porque no ha habido un trasegar más allá de las fronteras a que la Junta realmente sea un organismo fuerte que respalde la profesión, ni una estrategia de operación que le permita ir más allá de la expedición de la matrícula y el registro de los contadores (Comunicación personal, 28 de septiembre de 2017).

Finalmente, el Profesor Hernando Bermúdez ${ }^{5}$ resalta que la JCC nunca ha tenido una modificación organizacional, siendo la reforma del año 2010 un

3 Presidente del Tribunal Disciplinario de la Unidad Administrativa Especial Junta Central de Contadores.

4 Contador Público de la Universidad de La Salle, cuenta con una amplia experiencia académica, investigativa y de proyección social. Con estudios superiores en Alta Gerencia en la Universidad de los Andes y Universidad Militar Nueva Granada; igualmente en Control Interno y de Gestión, en el Instituto de Estudios del Ministerio Público; Administración y Gestión de Crédito en la Escuela Nacional de Habitacao e Poupanca (ENHAP), Rio de Janeiro, Brasil.

5 Profesor asociado del Departamento de Ciencias Contables de la Facultad de Ciencias Económicas y Administrativas de la Pontificia Universidad Javeriana; caballero de la Orden Universidad 
cambio jurídico más, tal como pasar de ser una dependencia del Ministerio de Educación a ser Unidad Administrativa Especial, otorgarle personería jurídica, designarle funciones adicionales a las definidas en la Ley 43 de 1990, entre otros (Comunicación personal, 29 de septiembre de 2017).

En base a las consideraciones planteadas, es preciso afirmar que la JCC no sufrió alteraciones significativas que le permitieran cumplir su rol como órgano disciplinario de conformidad con la Ley 1314, es decir, la modificación que en ésta se indica es un eslabón que no logró integrarse satisfactoriamente para garantizar el debido cumplimiento del proceso, lo cual significó que su ejercicio continuara con falencias tal y como se venía realizando. Sin duda, la escasa participación de la JCC en la convergencia a estándares internacionales, etapa coyuntural para la profesión contable, dejó repercusiones significativas que confluyen en el incumplimiento por parte de los contadores públicos en la aplicación de la nueva normatividad y su poca proactividad en el proceso.

En adición a lo anterior, cabe destacar un llamado realizado por la JCC y el CTCP en el año 2017 dirigido al Gobierno colombiano, para que impulse los cambios estructurales necesarios en el ente de supervisión que faciliten el cumplimiento de sus labores y, además, expresan la latente preocupación frente al desequilibrio que se presenta en la JCC entre los requerimientos que conlleva el desempeño de sus responsabilidades y los recursos que posee para ello (CTCP, 2017). Así pues, cuando por parte del mismo ente se solicitan cambios estructurales siete años después de la modificación efectuada, se corrobora la opinión generalizada de los expertos contables acerca de la nula o poca efectividad que se derivó del ajuste institucional realizado.

Otro de los factores considerados por el Gobierno Nacional en la Ley 1314 para fundamentar su cumplimiento, hace referencia a que el ente supervisor contaría con los medios económicos necesarios para el ejercicio de sus funciones, lo cual tendría afectación en la JCC, puesto que su deber ser de supervisar a doscientos treinta y un mil seiscientos sesenta y ocho (231.668) contadores públicos activos en Colombia (JCC, 2017), es una tarea que requiere aparte de una estructura fuerte de estrategias y personal, la existencia de recursos para tal fin. En este sentido, suscita comentar que los Ministerios encargados decidieron no asignarle recursos a la JCC y, en contrario, le están destinando recursos que ella misma recauda. Pese a ello, los recursos con los que cuenta la JCC pueden ser significativos, pero no son usados como es debido para atender las necesidades prioritarias para el cumplimiento de sus funciones (H. Bermúdez, comunicación personal, 29 de septiembre de 2017).

Se pone en evidencia la falta de otro eslabón requerido para garantizar el debido cumplimiento del proceso de convergencia que, aunado al aspecto

Javeriana; socio honorario de la Sociedad de Contadores Javerianos; miembro del Colegio de Abogados Javerianos y consultor independiente especialmente en derecho contable. 
Botero, A.; Marulanda, C.; Alvarez, M.; Muñoz, L. Proceso de implementación de las NIIF...

relacionado con la modificación, deja entrever que la JCC difícilmente ha podido jugar un papel relevante y que realmente agregue valor, ya que no ha dispuesto de los elementos necesarios para ello, sin mencionar los aspectos referentes al personal del Tribunal Disciplinario, mencionados en apartados anteriores.

En una encuesta realizada a contadores públicos con experticia en NIIF acerca del papel jugado por la JCC en el proceso de implementación de las NIIF en Colombia, el 55\% de los encuestados consideran que la entidad en mención no ha ejecutado solicitudes, inspecciones ni sanciones a los contadores públicos en aras de supervisar el cumplimiento del nuevo marco normativo en el desarrollo de sus labores o lo ha hecho deficientemente, mientras que tan solo el $12 \%$ de los encuestados, afirman que la JCC lo ha hecho total o suficientemente.

Ilustración 5. Solicitudes, inspecciones y sanciones realizadas por la JCC

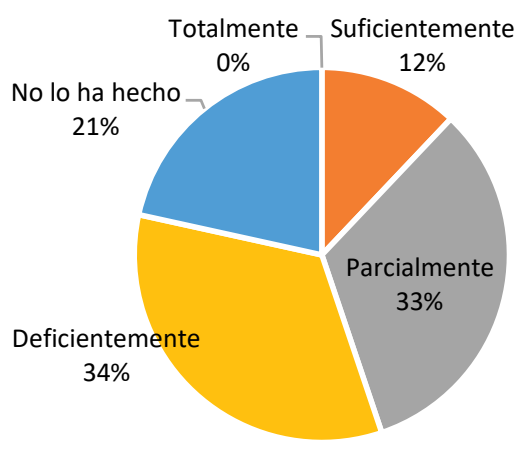

Fuente: elaboración propia.

Ciertamente, las acciones llevadas a cabo por el Tribunal Disciplinario con relación a la implementación de las NIIF son mínimas, puesto que hasta ahora se ven abocados a manejar el nuevo marco normativo contable, a causa de casos de alto impacto relacionados con NIIF que se van sumando a la lista de expedientes que deben revisar con el poco equipo de trabajo disponible, según lo afirma Eduardo Forero (Comunicación personal, 29 de septiembre de 2017). No queda duda que la JCC acciona cuando se le presenta información por diferentes medios, es decir, es netamente reactiva, pero nunca ha funcionado de manera proactiva y, aún con las NIIF, cuando se esperaban cambios estructurales, su funcionamiento continúa intacto.

\section{Función ejercida por la superintendencia de sociedades con presencia insuficiente}

El comportamiento de las autoridades de vigilancia cuando se presentan cambios estructurales y relevantes en los procesos que vigilan suele ser muy 
laxo, dado que es común otorgar un periodo de tiempo en el cual los vigilados puedan adoptar los cambios en su accionar, considerando los impactos que generan los cambios y la resistencia que éstos traen consigo. Tras la implementación de las NIIF en las entidades colombianas, la Superintendencia de Sociedades no ha sido ajena a lo anterior, ya que ha iniciado su proceso de vigilancia con sanciones pedagógicas en los primeros años de adopción del nuevo marco normativo, en aras de brindar apoyo a las entidades en el proceso de transición a la nueva normativa y, posteriormente, ha impuesto sanciones en aquellos casos que las entidades hayan reiterado el incumplimiento a ciertos requisitos exigidos.

A continuación, se ilustran los resultados arrojados por una encuesta realizada a contadores expertos en NIIF acerca de la aplicación por parte de la Superintendencia de Sociedades de sanciones pertinentes a las MIPYMES que no han cumplido con el proceso de convergencia, los cuales dejan entrever que la percepción del $64 \%$ de los encuestados conviene en que la Superintendencia no ha aplicado sanciones en relación a este proceso o lo ha hecho de manera deficiente:

Ilustración 6. Aplicación de sanciones por la Superintendencia de Sociedades a las MIPYMES

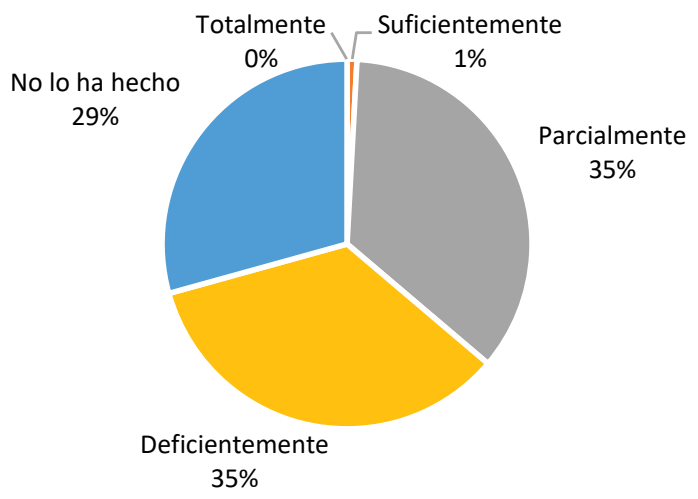

Fuente: elaboración propia.

La Superintendencia de Sociedades puede catalogarse como una de las entidades que ha liderado e instruido el proceso de convergencia, siendo una muestra de ello el desarrollo de una herramienta tecnológica, denominada SIRFIN, diseñada con el fin que las entidades bajo la supervisión de la Superintendencia pudieran reportar su información bajo el lenguaje $\mathrm{XBRL}^{6}$

6 Lenguaje universal creado por Charles Hoffman en el año 1998, con el fin de simplificar la mecanización del intercambio de información financiera a partir del lenguaje XML. El objetivo del lenguaje XBRL, es facilitar el reporte y análisis de la información financiera de las entidades en la 
Botero, A.; Marulanda, C.; Alvarez, M.; Muñoz, L. Proceso de implementación de las NIIF...

(Extensive Business Reporting Language). Sin duda, esta herramienta ha contribuido extensiblemente al logro de un proceso de reporte de información financiera con mayor efectividad por parte de las entidades. Adicionalmente, la Superintendencia de Sociedades ha puesto a disponibilidad del público un portal tecnológico de información empresarial en línea, por medio del cual proporciona la información financiera pública de las entidades supervisadas.

Ahora bien, para garantizar el cabal cumplimiento de sus funciones, la Superintendencia, además de disponer de muy buenas herramientas en cuanto a sistemas de información, debió establecer herramientas de supervisión de la información reportada por medio de tales sistemas, con el fin de evaluar su razonabilidad y su calidad, de conformidad con los criterios contables y financieros vigentes, para que pudiesen afirmar que en efecto los reportes cumplían con las exigencias normativas. Lo anterior, debido a que es usual que cuando las entidades son solicitadas por la Superintendencia de Sociedades, identifiquen las operaciones básicas para simular que implementaron NIIF, limitándose a hacer las correcciones principales sobre las cuentas que sufren mayor afectación bajo el nuevo marco normativo, pero no realizan un proceso a cabalidad que garantice la implementación de la nueva normatividad.

Estupiñán \& Estupiñán (2015), plantean que las superintendencias han solicitado información de carácter obligatorio a las empresas que inspeccionan, vigilan o controlan por medio de circulares; no obstante, aquellas suelen limitarse a entregar los requerimientos por mero cumplimiento legal y evitar sanciones, lo que no garantiza que se lleve a cabo el proceso completo y de manera efectiva.

Para el año 2015, la Superintendencia de Sociedades requirió mediante la Circular 115-000008 la información mencionada a las sociedades clasificadas en el Grupo I - NIIF Plenas. Para el año 2016, mediante las Circulares 201-000009 y 201-000010 la solicitó a las sociedades comerciales del Grupo I y del Grupo II NIIF PYMES, respectivamente. Finalmente, para el año 2017, emitió la Circular 201-000004 en la cual requiere la información a las sociedades de Grupo I y Grupo II. Se evidencia claramente que la Superintendencia de Sociedades no ha incluido al Grupo III dentro de las sociedades a las cuales ha requerido información.

Es posible afirmar que, tras la implementación del nuevo marco normativo en convergencia a las NIIF, la Superintendencia de Sociedades ha seguido trabajando sobre el mismo grupo de entidades que siempre ha trabajado, el cual es un grupo muy pequeño en relación al universo de entidades que conforman el sistema colombiano. El grupo de entidades supervisado por la Superintendencia de Sociedades está conformado, principalmente, por

web, permitiendo la generación de informes financieros personalizados en un formato compatible con la mayoría de las aplicaciones informáticas de contabilidad y de análisis de datos. 
empresas grandes pertenecientes al Grupo II al no cotizar en el mercado de valores ni ser entidades financieras. La cobertura reducida por parte de la Superintendencia se debe en gran medida a que ésta no está pensada para tener presencia en la totalidad de entidades que le compete, así como ocurre con la inmensa mayoría de organismos de inspección y vigilancia en Colombia, dícese de la policía, la DIAN, los ministerios, la JCC, que tienen de común denominador la carencia de recursos para vigilar lo que en teoría tendrían que vigilar ( $\mathrm{H}$. Bermúdez, comunicación personal, 29 de septiembre de 2017).

Sin embargo, en lo que refiere a las MIPYMES, es importante mencionar que este atañe un grado de dificultad sobresaliente para la Superintendencia de Sociedades considerando que el $99 \%$ de las empresas colombianas se encuentran clasificadas en tal grupo. Aun así, bajo el entendido de que la Superintendencia de Sociedades ha requerido un grupo limitado de empresas, y ni el total de las requeridas han dado respuesta positiva a las solicitudes realizadas, es cuestionable cuál será la situación de las que no fueron requeridas.

Finalmente, es menester aludir que uno de los principales objetivos del Gobierno Nacional al migrar hacía NIIF, fue formalizar las entidades colombianas, en especial aquellas del Grupo III, pues muchas de éstas se encontraban bajo informalidad. No obstante, es cuestionable el cumplimiento de este propósito, pues las entidades catalogadas en dicho grupo, no contaban ni cuentan con la infraestructura necesaria para dar aplicación a estos nuevos marcos normativos y las autoridades de vigilancia no brindan cobertura a este tipo de entidades. Además, la relación existente entre el costo beneficio que implicaba a las entidades del Grupo III aplicar los nuevos marcos normativos era altamente desproporcionada y, en contraste, los beneficios que supondría la aplicación de las NIIF se evidenciarían especialmente en el Grupo I, lo que lleva a pensar que las NIIF se desarrollaron pensando más en las compañías grandes, centrando muy poco su atención en MIPYMES, tanto por parte de los reguladores como de las autoridades de vigilancia, que son las que componen casi que en su totalidad el sistema empresarial colombiano.

\section{IX.Falencias y alternativas de la infraestructura contable colombiana de cara a las NIIF}

Tras haber analizado el funcionamiento de la JCC y de la Superintendencia de Sociedades y la participación que éstas han tenido a lo largo del proceso de convergencia a estándares internacionales, es importante traer a colación otros factores que sin duda han supuesto una serie de dificultades en la aplicación del proceso de convergencia y que ponen en evidencia que el país requiere con prontitud la integración y el fortalecimiento de elementos que van desde el Gobierno Nacional hasta los gerentes de las compañías, en aras de construir 
Botero, A.; Marulanda, C.; Alvarez, M.; Muñoz, L. Proceso de implementación de las NIIF...

un sistema contable de calidad y que responda a las necesidades del mercado financiero contemporáneo.

En primera instancia, es bien sabido que el país se encuentra atravesando una etapa de recorte presupuestal, lo cual afecta directamente la destinación de recursos para las autoridades de vigilancia definidas en la Ley 1314 como organismos encargados de velar por su debido cumplimiento. A causa de la complejidad del proceso de convergencia y de los cambios relevantes que de él se derivan, era necesario impulsar y fortalecer el funcionamiento de tales autoridades para que brindaran acompañamiento tanto a las empresas como a la profesión contable, lo cual implicaba forzosamente la asignación de recursos. Tal como alude Franco (Comunicación personal, 28 de agosto de 2017):

$\mathrm{Si}$ bien pueden haberse destinado recursos, éstos no fueron suficientes o hubo ineficiencias en su manejo. Aunque existen las instituciones, como tal para el Gobierno Nacional el tema de la contabilidad no ha sido un tema prioritario y más en la coyuntura actual.

Lo anterior, probablemente bajo la premisa por parte del Gobierno que la aplicación de las NIIF es responsabilidad directa de los contadores y de las compañías, quienes deben cumplir con su implementación, mientras que las autoridades solo deben ejercer vigilancia por excepción demandando una menor cantidad de recursos en ello. Pese a la falta de asignación de recursos a las autoridades, éstas han actuado de manera muy tímida y han desempeñado con poca fuerza sus funciones, lo cual ha confluido en que las empresas no se sientan vigiladas por la Superintendencia ni obligadas a dar cumplimiento a la nueva normatividad y, asimismo, que los contadores no sientan el respaldo ni el debido acompañamiento por parte de la JCC.

Aparte de lo anterior, las MIPYMES no han impulsado las NIIF en sus organizaciones debido a que muy pocas ven beneficios con su aplicación debido al pensamiento generalizado de que el costo de la implementación de NIIF es superior a la utilidad que de ello se deriva y, además, a algunas no les interesa mostrar la realidad financiera de la empresa, dado que podrían incrementarse los pagos tributarios. También, es indudable que muchas de las empresas que actualmente tienen la obligación de aplicar NIIF Pymes o contabilidad simplificada anteriormente estaban limitadas a llevar contabilidad fiscal o en algunos casos, ni siquiera llevaban contabilidad.

La exagerada instrumentalización ha seguido primando sobre la utilidad de la información financiera, siendo esta última perseguida por los estándares internacionales, conllevando a que muchas empresas, en especial las pertenecientes al Grupo II y Grupo III, apliquen las NIIF por mero cumplimiento legal sin percatarse de los objetivos, implicaciones y beneficios perseguidos por el país tras converger a prácticas contables internacionales. 
Es necesario reconocer que las NIIF no son solo contabilidad, por tanto, no competen solo al contador sino a toda la organización, las NIIF son información financiera y gran parte del éxito de su implementación en las empresas depende de la gerencia, quien escasamente conoce del proceso contable y le brinda relativamente poca importancia, por lo que se requería que la Superintendencia orientara y creara conciencia en los gerentes de las organizaciones para que ellos entendieran los beneficios arraigados a la aplicación de estándares internacionales y se apropiaran del proceso, pero esto no ocurrió, con el agravante que fueron limitados los contadores que lideraron la adopción de las NIIF en las entidades.

Era indispensable una orientación oficial a la gran cantidad de contadores del país con el fin que se garantizara que la profesión contable se capacitara en estándares internacionales y se certificara su idoneidad para asumir tan dispendioso reto. Al no existir esta orientación, la cantidad de contadores capacitados es significativamente baja, puesto que muy pocos tienen los recursos para tal fin y, en su mayoría, no recibieron apoyo por parte de las empresas (O. Torres, comunicación personal, 29 de septiembre de 2017).

En esencia, los problemas presentados a lo largo del proceso de convergencia no son propios de los estándares internacionales de información financiera, sino que responden a un conglomerado de falencias que caracterizan la infraestructura contable de Colombia, es decir, si se desea tener informes de calidad, además de tener normas de información financiera adecuadas, se deben tener personas que estén calificadas para poderlas aplicar, poseer unos mecanismos de supervisión, monitoreo y fiscalización del cumplimiento de esas normas y, además, tener apoyo político y financiero del alto gobierno, ya que sin éste las discusiones técnicas para lograr mejorar las falencias identificadas no van a ser suficientes (W. Franco, comunicación personal, 28 de agosto de 2017).

Uno de los principales pilares que fundamentan el adecuado funcionamiento del sistema contable en Colombia es el rol que ejerce la Junta Central de Contadores, que sin duda requiere una reestructuración de fondo, a partir de cambios institucionales que vayan más allá de los cambios jurídicos que se le han efectuado y que impliquen reinventar el modelo de operación que desde su creación ha tenido.

Dicha reestructuración se enfoca esencialmente en el Tribunal Disciplinario respecto a la planta de personal, dado que con su conformación actual no logra dar cumplimiento eficiente a su función. Así pues, es menester que el Tribunal esté integrado por una planta de personal suficiente, permanente e idónea, es decir, un número considerable de funcionarios de tiempo completo y vinculados a la entidad que puedan estudiar la totalidad de casos que llegan evitando que se venza el término de revisión y que, específicamente, el personal encargado 
Botero, A.; Marulanda, C.; Alvarez, M.; Muñoz, L. Proceso de implementación de las NIIF...

de preparar y formular el caso en lo que concierne al debido proceso tengan las capacidades y la experticia necesaria en derecho contable.

Solo una vez se ha logrado lo anterior, será posible plantear cambios adicionales encaminados a que la Junta Central de Contadores actúe proactivamente demostrando que es la autoridad disciplinaria y garante del actuar de la profesión contable, tomando las medidas necesarias para verificar el accionar de los contadores públicos por orden de la misma entidad más no por quejas o informes que le sean presentados. Tras fortalecer el proceso disciplinario, la JCC podrá identificar opciones de mejora e implementar herramientas de prevención y de apoyo para los contadores en aras de que la profesión contable actúe conforme a lo establecido normativamente, tanto por su idoneidad para darle cumplimiento como por la obligatoriedad dada la presencia ejercida por parte de la JCC (L. Forero, Comunicación personal, 29 de septiembre de 2017).

Para garantizar la idoneidad de los profesionales contables del país, es menester evaluar las barreras de entrada a la profesión contable y el seguimiento de las competencias de la misma, considerando la multiplicidad de programas de contaduría pública que son ofrecidos en el país de los cuales muy pocos poseen acreditación por parte del Ministerio de Educación, siendo éste un factor influyente en la cantidad significativa de contadores públicos actualmente registrados en el país, a quienes se les ha otorgado la tarjeta profesional con exigencias poco rigurosas que en cierta medida no avalan la calidad de profesionales contables que diariamente tienen la potestad de dar fe pública. Así mismo, la evaluación de las competencias de los contadores no existe, precisamente por el carácter indefinido que posee la tarjeta profesional.

En este orden de ideas, se requiere sensibilizar y capacitar al personal directamente implicado en los procesos contables y financieros, generando una cultura de autoaprendizaje, que se facilita por medio de las herramientas informáticas que ofrece el mundo globalizado, y una cultura de autorregulación en la que los contadores reconozcan por sí mismos la obligatoriedad de cumplir las disposiciones legales dado su condición de dar fe pública y por la ética profesional que debe acompañar su quehacer profesional. Bien es sabido que la contabilidad es una profesión que requiere actualización constante para estar a tono con las circunstancias, por lo que es inadmisible pretender que el pregrado por si solo permita a los contadores públicos subsistir en un mercado que cada vez exige más y en el cual no existen las fronteras.

Todo cambio implica resistencia y más cuando sus afectaciones son significativas, tal como el proceso de implementación de una nueva normativa como los estándares internacionales de información financiera, en el cual se hace necesario que los reguladores y las autoridades de vigilancia acompañen a las empresas y a la profesión contable a lo largo del proceso, para que más 
allá de emitir las normas y estar a la espera de vigilar el debido cumplimiento de los resultados del mismo y aplicar las sanciones que sean necesarias, puedan afirmar que fueron partícipes del proceso apoyando a las entidades para que surtieran a cabalidad cada uno de sus pasos y puedan evaluar con un mayor grado de criterio los resultados que les sean entregados por las empresas al aplicar las NIIF y tengan certeza de la idoneidad de los profesionales contables al elaborar tales resultados gracias a su vasto conocimiento en el nuevo marco normativo. En efecto, muy seguramente si los reguladores y las autoridades de vigilancia solo se encargan de la emisión de las normas y de la verificación de su aplicación, respectivamente, tanto las entidades como la profesión, surtirán un proceso poco ortodoxo y por mero cumplimiento legal.

El proceso de aplicación de los estándares internacionales de información financiera requiere un fuerte proceso de sensibilización, que debe ser liderado por las autoridades mencionadas, para lograr involucrar a todos los funcionarios de la entidad en miras de descentralizar el proceso contable, concientizar a las diferentes áreas que son proveedoras de información contable o que tienen vinculación con ésta sobre su importancia en el proceso de generación de informes financieros de calidad y garantizar el cumplimiento de los objetivos propuestos con la convergencia.

En síntesis, las NIIF se tornaban como un tema necesario para el país, pero su aplicación hizo evidente muchas fallas desde varios ámbitos en el sistema contable colombiano como tal, incluyendo entre ellos, el apoyo del gobierno nacional, el funcionamiento de las autoridades de vigilancia, los contadores y los administradores de las entidades, las agremiaciones contables. Por tanto, se requiere que todos los actores involucrados en el proceso se apropien de su rol siendo las autoridades de vigilancia una de los pilares fundamentales que requieren una modificación para que el proceso de implementación se lleve a cabo eficientemente. El fortalecimiento de las autoridades de vigilancia de las que a lo largo del artículo se ha hecho mención hubiese significado un cambio drásticamente preciso para poner de manifiesto que el país migraría de la manera correcta hacia estándares internaciones de información financiera.

\section{Conclusiones}

Tras haber caracterizado el papel que han jugado las autoridades de vigilancia definidas en la Ley 1314 de 2009 para supervisar el debido cumplimiento del proceso de convergencia a estándares internacionales de información financiera, se evidencia que éstas no han ejercido a cabalidad las funciones conferidas en la mencionada Ley, debido principalmente a la carencia de elementos que poseen, tales como recursos, infraestructura, planeación y coordinación, para vigilar el ejercicio profesional del elevado número de 
Botero, A.; Marulanda, C.; Alvarez, M.; Muñoz, L. Proceso de implementación de las NIIF...

contadores y el accionar conforme a lo establecido en las leyes por parte de las empresas catalogadas como MIPYMES, bajo la nueva normatividad aplicable.

El Tribunal Disciplinario de la Junta Central de Contadores se ha caracterizado por operar de manera reactiva desde su creación y, si bien, se le han efectuado modificaciones, éstas solo han sido de carácter jurídico y no se han logrado cambios institucionales que influyan directamente en el funcionamiento de la entidad. Frente al proceso de convergencia a las NIIF, la Junta Central de Contadores no ha participado activamente en pro de supervisar el debido cumplimiento de la nueva normatividad por parte de la profesión contable y el desarrollo de sus funciones no ha tenido afectación alguna a lo largo de este proceso coyuntural, continuando enfocada esencialmente en su función de registro de los profesionales. Lo anterior, a raíz de las significativas deficiencias estructurales que históricamente ha presentado la entidad.

La Superintendencia de Sociedades desempeña sus funciones de inspección, vigilancia y control de las entidades de manera efectiva hasta donde el uso eficiente de los recursos que posee se lo permite, y pese a las dificultades que presenta para ejercer su rol, considerando a la multiplicidad de empresas que conforman el mercado colombiano. A lo largo del proceso de implementación de las NIIF, su papel ha sido relevante, liderando acciones importantes en lo que se refiere al acompañamiento de las entidades para transitar al nuevo marco normativo. No obstante, el ejercicio de su rol sobre las MIPYMES no ha sido tan notorio, debido a que ha focalizado su atención en la evaluación del debido proceso de convergencia en las empresas del Grupo I y del Grupo II.

En este sentido, es evidenciable que el Gobierno Nacional no advirtió eficazmente la estructura y el modo de operación o funcionamiento de las autoridades de vigilancia en materia contable y financiera, en aras de asegurar el debido cumplimiento del proceso de convergencia a estándares internacionales, puesto que, si bien en la Ley 1314 de 2009 se requirieron modificaciones para tales autoridades, éstas no surtieron efectos relevantes, lo que significó que el proceso de supervisión continuara con las falencias que siempre ha mantenido y no se tuvieran las herramientas necesarias para hacer frente a la vigilancia de la internacionalización de la información financiera colombiana.

Unido a ello, es importante mencionar la falta de coordinación entre las autoridades que forman parte del sistema contable, porque si bien cada una puede ser eficiente dando cumplimiento a sus funciones, es fundamental que éstas se unan para lograr objetivos comunes, porque de no ser así no se genera un valor agregado. Así pues, no basta con conocer los roles de cada autoridad si entre ellas mismas no se tiene claridad frente a lo que a cada una compete y se deja de lado el trabajo en armonía que deben realizar.

Es indiscutible que este proceso coyuntural para Colombia era un momento propicio para proyectar la profesión contable, dejando atrás el paradigma de su 
función meramente técnica y reconocer la utilidad de la información financiera dentro del mercado en general. Sin embargo, para ello era menester definir un plan de acción con el fin de fortalecer la infraestructura contable, logrando integrar los esfuerzos de todas las instituciones y aplicar las oportunidades de mejora que se han identificado, ya que puede existir una norma de calidad mundial, pero si no existe el personal idóneo para aplicarla y no se tienen unos mecanismos eficientes de monitoreo, supervisión y fiscalización, no será posible obtener informes de calidad y la actuación de los contadores no va a ser efectiva, porque al tener un sistema contable, se requiere una estrategia integral que permita su debido funcionamiento.

\section{Referencias bibliográficas}

Álvarez, M. C., \& Muñoz, L. M. (21-24 de Octubre de 2014). Principales impactos en la información contable y financiera de las empresas, como consecuencia de la adopción de las normas internacionales de informacion financiera: caso colombiano. Asamblea General de Asociación Latinoamericana de Facultades y Escuelas de Contaduría y Administración. Ciudad de Panamá.

Banco Mundial. (2005). Report on the Observance of Standards and Codes (ROSC) : accounting and auditing. Washington, DC. Recuperado el 7 de Mayo de 2017, de http://documents.worldbank.org/curated/en/353391468241455747/ColombiaReport-On-The-Observance-Of-Standards-And-Codes-ROSC-accounting-and-auditing

Casinelli, H. P. (Abril-Junio de 2013). Comentarios sobre la idoneidad de la NIIF para PYMES enfocada a las microentidades. Revista Internacional Legis de Contabilidad y Auditoría(54), 143-159.

Colmenares, L. A. (Octubre-Diciembre de 2011). El proceso de convergencia a estándares internacionales en Colombia: avances temáticos y regulativos. Revista Internacional Legis de Contabilidad y Auditoría(48), 5-18.

Congreso de la República de Colombia. (13 de Diciembre de 1990). Artículo 20. Ley 43 de 1990. Por la cual se reglamenta la profesión del contador publico. Bogotá, D.C., Colombia.

Congreso de la República de Colombia. (13 de Diciembre de 1990). Artículo 83, 84 y 85. Ley 222 de 1995. Por la cual se modifica el Libro II del Código de Comercio, se expide un nuevo régimen de procesos concursales y se dictan otras disposiciones. Bogotá, D.C., Colombia.

Congreso de la República de Colombia. (13 de Julio de 2009). Artículo 9. Ley 1314 de 2009. Por la cual se regulan los principios y normas de contabilidad e información financiera y de aseguramiento de información aceptados en Colombia, se señalan las autoridades competentes, el procedimiento para su expedición y se determinan las entidades responsables de vigilar su cumplimiento Bogotá, D.C., Colombia.

Consejo Técnico de la Contaduría Pública. (Julio-Septiembre de 2004). Regulación y normalización contable: análisis de la adopción en Colombia de los estándares de contabilidad, auditoría y contaduría. Revista Internacional Legis de Contabilidad y Auditoría(19), 53-139. 
Botero, A.; Marulanda, C.; Alvarez, M.; Muñoz, L. Proceso de implementación de las NIIF...

Consejo Técnico de la Contaduría Pública. (24 de Febrero de 2017). CTCP y JCC hacen un llamado al Gobierno Nacional para promover cambios estructurales que faciliten la función de supervisión de la Junta Central de Contadores. Bogotá. Recuperado el 05 de Mayo de 2017, de http://www.ctcp.gov.co/ctcp_news.php?NEWS_ID=580\&HASH $=069 \mathrm{~d} 3 \mathrm{bb} 002 \mathrm{acd} 8 \mathrm{~d} 7 \mathrm{dd} 095917 \mathrm{f} 9 \mathrm{efe} 4 \mathrm{cb}$

Departamento Nacional de Planeación [DNP]. (2005). Información MIPYMES censo 1990 y 2005. Recuperado el 23 de Marzo de 2017, de www.dnp.gov.co: https://colaboracion. dnp.gov.co/CDT/Desarrollo\%20Empresarial/INFORMACION_MIPYMES_act2012.pdf

Estupiñán, R., \& Estupiñán, O. (Agosto de 2015). Experiencias en la Implementación NIIF para las PYMES Grupo 2 en Colombia. Recuperado el 15 de Marzo de 2017, de http:// www.fedecop.org/Conferencias/4.\%20Rodrigo\%20Estupinan $\% 20$-\%20Experiencias $\% 20$ en\%20implementacion\%20de\%20NIIF\%20Pymes\%20en\%20Colombia.pdf

Ferrer, A. (2013). Análisis del proceso de convergencia a Normas Internacionales de Informacion Financiera desde los factores intrínsecos al sistema contable en Colombia. Revista Cuadernos de Contablidad, 14(36), 971-1007.

Junta Central de Contadores. (2017). Oficina de Registro - Estadisticas 2016. Recuperado el 06 de Mayo de 2017, de https://docs.google.com/spreadsheets/ d/1rWgADPeZXID1 ovRGzAH5Sq37_xR--Qb2UGvxAENg71w/edit\#gid=1792958402

López, C., \& Zea, F. (Octubre/Diciembre de 2011). Convergencia a estándares internacionales de información financiera y de aseguramiento en Colombia: análisis de documentos de direccionamiento estratégico del CTCP. Revista Internacional Legis de Contabilidad y Auditoría(48), 97-134.

Machado, M. A. (Enero-Junio de 2015). De la regulación a la planificación: un tránsito necesario para construir pensamiento contable. Revista Contaduría(46), 54.

Mantilla, S. (4 de Marzo de 2017). NORMATIVA COLOMBIANA NIIF-NIA: Ineficaz y de dudosa obligatoriedad legal. Recuperado el 14 de Marzo de 2017, de http://www.samantilla1. com: https://media.wix.com/ugd/e8a62c_e39fcb879334445abe078daa7559a412.pdf

Ministerio de Comercio, Industria y Turismo. (23 de Agosto de 2011). Artículo 4. Decreto 3048 de 2011. Por el cual se crea la Comisión Intersectorial de Normas de Contabilidad, de Informacion Financiera y de Aseguramiento de la Información Financiera. Bogotá, D.C.

Ministerio de Comercio, Industria y Turismo. (18 de Mayo de 2012). Artículos 13 y 14. Decreto 1023 de 2012. Por el cual se modifica la estructura de la Superintendencia de Sociedades y se dictan otras disposiciones. Bogotá, D.C.

Ministerio de Comercio, Industria y Turismo. (14 de Diciembre de 2015). Decreto 2420 de 2015. Por medio del cual se expide el Decreto Único Reglamentario de las Normas de Contabilidad, de Información Financiera y de Aseguramiento de la Información y se dictan otras disposiciones. Bogotá, D.C. 